\title{
ENTREVISTA
}

\section{AS NOVAS FORMAS DE ENSINAR E APRENDER}

O Congresso de Tecnologia na Educação, que ocorre no Senac em Caruaru, Pernambuco, de 18 a 20 de setembro deste ano, terá mesa-redonda com os dois professores aqui entrevistados. Eles dialogam sobre as novas formas de ensinar e aprender com o uso das tecnologias. Também refletem sobre as competências técnicas e socioemocionais para o sucesso profissional no século 21.

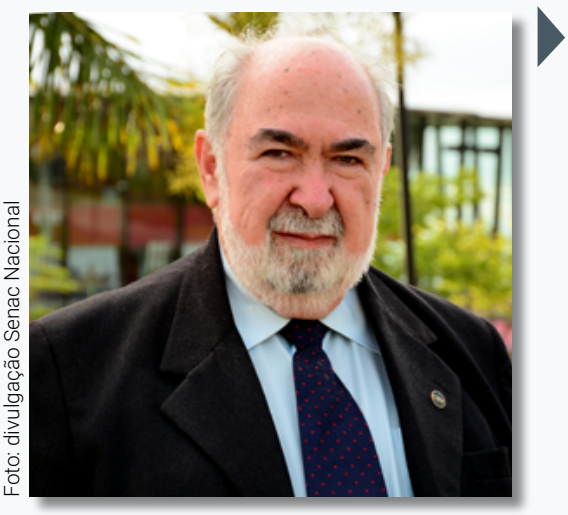

\section{Francisco Aparecido Cordão}

Educador, sociólogo e filósofo. Graduado em Filosofia e Pedagogia. Especialista em Educação Profissional, Administração Educacional e Sociologia da Educação. Tem atuado como Conselheiro nos Conselhos de Educação do Município e do Estado de São Paulo e na Câmara de Educação Básica do Conselho Nacional de Educação (CNE). Representou o Brasil no Mercosul Educacional. Atuou durante mais de trinta anos no Senac em São Paulo. Titular da Cadeira 28 na Academia Paulista de Educação. Presta serviços educacionais a Sistemas, Organizações e Instituições Educacionais tais como Senac, Sesc e Representação da Organização das Nações Unidas para a Educação, a Ciência e a Cultura (Unesco) no Brasil. E-mail:facordao@uol.com.br

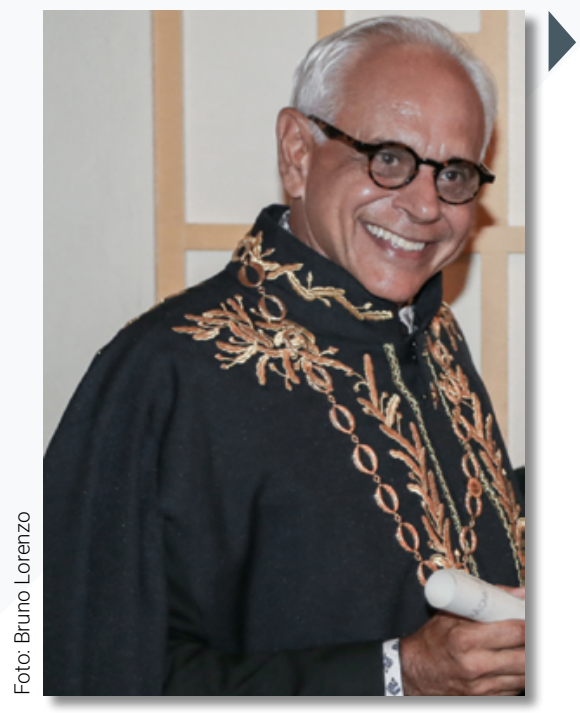

\section{Ronaldo Mota}

Diretor científico da Digital Pages e membro da Academia Brasileira de Educação. Atua nas áreas de Novas Tecnologias e Metodologias Inovadoras em Educação. Anteriormente, foi professor titular de Física da Universidade Federal de Santa Maria e pesquisador do Conselho Nacional de Pesquisa Científica e Tecnológica (CNPq). Realizou pós-doutoramento nas Universidades de Utah/USA e British Columbia/Canadá. Foi Professorial Visiting Fellow no Institute of Education - University of London/UK, chanceler do Grupo Estácio, reitor da Universidade Estácio de Sá, secretário nacional de Desenvolvimento Tecnológico e Inovação, secretário de Educação Superior, secretário de Educação a Distância e ministro interino do Ministério da Educação. Condecorado pela Presidência da República como Comendador na Classe Grã-Cruz da Ordem do Mérito Científico. E-mail: ronamota@gmail.com 
FAC- Do ponto de vista metodológico, neste século marcado por vertiginoso desenvolvimento científico e tecnológico, que formas inovadoras de ensinar e de aprender você julga essenciais para serem desenvolvidas pelos nossos professores?

RM- As formas com que aprendemos e ensinamos têm mudado significativamente ao longo das quase duas décadas deste século, mas as grandes transformações ainda estão por vir. Isso decorre em função das características específicas das sociedades nas quais os processos de aprendizagem ocorrem.

No século passado, o modelo de desenvolvimento adotado demandou profissionais que não existiam antes e sofisticou as especializações das profissões que já eram conhecidas. As escolas, seus professores e os métodos foram eficientes e eficazes em atender às exigências do mercado e às expectativas dos cidadãos. Para cada carreira, foram prescritas diretrizes gerais contemplando conteúdos, bem como procedimentos e técnicas a eles associados.

Os percursos educacionais, no século 20 , eram razoavelmente simples e funcionavam. Completados os percursos previstos, após avaliações calcadas em testes de memória, em geral respondidos individualmente, os formandos eram agraciados com certificados ou diplomas, os quais atestavam conhecimentos e os habilitavam a migrar para as etapas seguintes ou ao exercício pleno das respectivas ocupações.

Em torno da virada deste século e milênio, as mudanças se aceleraram de forma exponencial, motivadas pelo ingresso no universo digital, deixando rapidamente para trás as realidades analógicas de outrora. $\mathrm{O}$ advento das tecnologias digitais impactou, rápida e profundamente, todas as áreas de conhecimento e todos os setores de atividades humanas, incluindo educação. Aquilo que funcionava bem na área da aprendizagem, definitivamente, já não funciona mais.

Entender as novas e complexas situações educacionais passa por incorporar a imprevisibilidade, exigindo formar pessoas com capacidade de se adaptarem rapidamente aos inéditos contextos e circunstâncias, sejam eles quais forem. Ficar restrito às receitas já prontas, nos moldes dos tempos passados, tem como consequência limitar os profissionais a trabalhos rasos, subvalorizados e sujeitos a serem, gradativamente, substituídos por máquinas e algoritmos.

Os chamados trabalhos profundos, valorizados e compatíveis com o mundo contemporâneo, demandam pessoas capazes de irem muito além de processos memorizáveis. Exigem uma educação que ouse transcender o ensino tradicional, incorporando características que antes eram marginalmente consideradas.

Memória está associada, de forma simplificada, ao conjunto de conteúdos mais tradicionais, tendo papel relevante nos processos cognitivos, especialmente na absorção de conhecimentos básicos, entre eles: 1) letramento geral, capacidade comprovada de escrever e interpretar texto, e o letramento matemático; 2) letramento digital, incluindo o domínio de plataformas, softwares e aplicativos; e 3) capacidade de entender aspectos culturais, artísticos, históricos, geográficos etc. 
As habilidades socioemocionais, associadas à metacognição, estão acopladas, principalmente, a aspectos comportamentais, envolvendo a capacidade do educando de refletir sobre a própria aprendizagem. Assim, aliado ao domínio dos conteúdos, quanto aos aspectos metacognitivos, pretende-se que o educando: 1) seja capaz de aprender a aprender continuamente ao longo da vida, ampliando sua própria consciência acerca dos mecanismos segundo os quais ele aprende; 2) demonstre capacidade analítica para resolver problemas práticos, ou seja, embasado no conhecimento do método científico e na familiaridade com pensamentos críticos, desenvolva o domínio de raciocínios abstratos sofisticados; 3 ) esteja habituado a juntar diferentes áreas do saber, com especial disposição para a área de gestão de informações, incluindo o domínio de linguagens e de plataformas digitais; 4) tenha efetiva habilidade de comunicação, sabendo lidar com pessoas, incluindo promover mediações com flexibilidade e competência em todos os contextos; 5) tenha inteligência emocional desenvolvida, incluindo perseverança, empatia, autocontrole e capacidade de gestão emocional coletiva; 6) demonstre disposição plena para o cumprimento simultâneo de multitarefas, propiciando capacidade de análises apuradas e de tomada de decisões; e 7) colabore em equipe de forma produtiva, sendo respeitoso e cordial, entendendo as características individuais e as peculiaridades das circunstâncias, promovendo ambientes criativos e empreendedores, resultantes de processos coletivos e cooperativos.

Ambientes virtuais de aprendizagem facilitam a coleta e análise de dados, tanto acerca do domínio de conteúdos como de aspectos comportamentais de cada estudante. Analítica da aprendizagem (learning analytics) viabiliza conhecer melhor cada educando e, em conjunto com ele, favorecer sua própria reflexão sobre o processo de aprendizagem, determinar trilhas educacionais personalizadas.

Em suma, em termos metodológicos, memória e habilidades socioemocionais, tal como cognição e metacognição, não se contrapõem; elas se complementam. O desenvolvimento da habilidade de aprender a aprender só é possível ao longo do processo de absorção de conteúdos. Ainda que, por vezes, seja mais relevante ampliar a consciência de como e em que contexto se aprende do que o que foi efetivamente aprendido.

É andando que se desenvolve a capacidade de andar. Até o ponto em que a reflexão madura acerca do próprio caminhar emancipa o educando em direção à aprendizagem independente, preparando-o para toda a vida.

FAC- A atual Lei de Diretrizes e Bases da Educação Nacional (LDB) define que a Educação "tem por finalidade o pleno desenvolvimento do educando, seu preparo para o exercício da cidadania e sua qualificação para o trabalho". Como as novas tecnologias educacionais disponíveis podem ajudar os nossos professores nessa tarefa?

RM- Educação, conforme disposto constitucionalmente, implica a preparação do educando para a cidadania, envolvendo a qualificação para o trabalho. Assim, educar envolve mais do que transmitir conhecimento. Entre as tarefas dos professores está 
colaborar em abrir as portas para que cada educando desfrute ao máximo daquilo de que, potencialmente, todos dispomos: inteligência, entendimento e sabedoria.

Dentre todas as espécies, somos a única que possui a incrível habilidade de transmitir cultura e conhecimento de forma organizada e consciente aos nossos descendentes. Os mais diversos ensinamentos, técnicas e procedimentos eram e são transmitidos pelos mestres aos seus aprendizes, os quais, após ritos de aprendizagem, se transformam em profissionais e cidadãos mais bem preparados.

Assim tem sido ao longo dos tempos. Porém, atualmente, vivemos grandes desafios, especialmente pela abrupta emergência das tecnologias digitais que a tudo modifica e transforma. Educar, mais do que nunca, é emancipar o educando para ser capaz de enfrentar problemas inéditos.

Contemporaneamente, educar é promover a aprendizagem independente ao longo de toda a vida, entendendo que cada educando aprende de maneira única e personalizada e que todos aprendem, em qualquer lugar e o tempo todo. Educar é também entender o outro e fazer algo a partir disso, aprendendo a trabalhar em equipe de forma cooperativa e solidária.

Por fim, temos, como educadores, a possibilidade de contribuir para que o educando se emancipe, dominando a arte de aprender a aprender continuamente, gerando as condições para um desenvolvimento econômico, social e ambiental sustentável.

\section{FAC- Em meio à revolução digital que estamos vivenciando neste século marcado pela crescente complexidade na resposta a desafios pessoais e sociais, cada vez mais incertos e inusitados, quais são os valores da educação que devem ser cultivados pelos professores?}

RM- De certa forma, os valores educacionais a serem cultivados pelos professores têm mantido uma positiva relação e coerência ao longo do tempo. O drama é que os tempos têm se alterado radicalmente, tornando as missões e, consequentemente, os valores associados, cada vez mais complexos.

Ou seja, ser educador depende dos tempos e dos contextos. Nas sociedades primitivas já havia a figura do educador, ainda que difusa. A geração mais nova aprendia com a geração mais antiga a arte da sobrevivência, bem como as regras de cooperação e do convívio em grupo. Havia rituais de passagem, em alguns casos, bem organizados, quando ciclos de aprendizagem se completavam. As tarefas do educador foram, com o tempo, ficando mais bem definidas, à medida que a sociedade se tornava mais complexa.

No mundo ocidental, surgiram os sofistas e apareceu a escola como instituição estabelecida. $\mathrm{O}$ amadurecimento do método, em especial do método científico, consolidou as universidades como espaços não só de transmissão do conhecimento, mas também de produção de ciência, que gerou tecnologias e contribuiu com o molde das sociedades modernas. 
Nos últimos séculos, a receita básica era o domínio de conteúdos, procedimentos e técnicas apuradas, em que a especialização foi o marco do modelo de desenvolvimento baseado na linha de montagem. Tudo alicerçado em carreiras profissionais cada vez mais múltiplas e específicas, acompanhando o grau de complexidade das sociedades mais recentes.

Contemporaneamente, a adequação do educador aos tempos e a seus contextos é, de novo, um enorme desafio. Conteúdos, procedimentos e técnicas importam, mas já não são suficientes. Há que se incluir inéditos requisitos, envolvendo a arte de aprender continuamente, ao longo de toda a vida, e um conjunto de aspectos socioemocionais, igualmente importantes. Porém, seja nas sociedades primitivas, seja no mundo contemporâneo, sabemos identificar quem é o educador.

Interessante observar que ser educador não significa necessariamente ser o mais bem-informado, aquele que detém o maior conhecimento. Essa é a pessoa culta, que nem sempre é educador. O educador é aquele que, principalmente, cultiva o saber como processo, no qual conhecer mais emancipa o educando e o prepara à aprendizagem independente. 0 educador tem consciência plena que seu papel é se tornar, gradativamente, menos necessário e gosta disso, promove isso, fica feliz e se desapega do educando e aprende a cada vez que educa.

0 educador tem opinião, mas a sua opinião não o caracteriza. Ela pode ser qualquer uma. O que marca é como ele se comporta sobre todas as opiniões, especialmente sobre aquelas que não são as suas. Educar é entender o outro, incluindo compreender o que o outro pensa, por se colocar na posição dele. Mais do que isso, ao entendê-lo, fazer algo a respeito. Nesse sentido, as opiniões em si tornam-se quase que irrelevantes e a essência é a capacidade de entender racionalmente e transmitir a beleza de um mundo com opiniões múltiplas e conflitantes. 0 educador pode ser gentil ou ranzinza, mas nunca indelicado. Pode ser simpático ou antipático, mas nunca grosseiro. Indelicadeza e grosseria não educam, violentam. 0 educador pacifica, esclarece, opina, respeita e educa.

O profissional da educação pode ter posição política, mas não é ela que define o seu ofício. Ela pode ser qualquer uma, podendo não ser a mesma sempre. Ele só não pode ser autoritário e inflexível. Porque a ausência do diálogo não é educação, é deseducação. A essência da aprendizagem é a multiplicidade de saberes, a dúvida, a contraposição, o debate, a especulação, a experimentação, os métodos e, especialmente, o respeito às diversas formas de conhecimento e a desejável riqueza de opiniões, quaisquer que elas sejam.

Quem educa pode ter fé ou não: pode ser monoteísta, das mais diversas crenças, pode ser politeísta, pode ser agnóstico ou mesmo ateu. Na verdade, o que é relevante é que o educador entenda a fé, ou a ausência dela, como respeitáveis traços culturais, individuais ou coletivos. São respeitáveis escolhas em si e legitimadas a priori. O que não atrai o educador - e o descaracteriza - é o proselitismo, porque de- 
seduca, oprime, se opõe à liberdade de escolha, à abertura dos espíritos e à flexibilidade do pensamento, elementos essenciais e indispensáveis na aprendizagem.

Aquele que educa entende que não existe uma forma única de inteligência. Inteligências são múltiplas. Existe a inteligência que decorre da memória e da capacidade de aprender conteúdos, a qual foi dominante em tempos recentes, mas já passados. Há a inteligência baseada na habilidade lógico-matemática. Há aqueles inteligentes por uma capacidade diferenciada corporal-cinestésica. Podemos falar de inteligência linguística, calcada especialmente na capacidade de entender e de elaborar textos complexos, facilitando a comunicação entre as pessoas. Há a inteligência existencial, resultante de processos intrapessoais de reflexões avançadas. Temos a inteligência via a empatia e a compaixão. Reconhece-se a inteligência musical e tantas outras equivalentes. Existem inteligências mais recentes, tais como a habilidade digital, associada à facilidade de lidar com plataformas e outras ferramentas do mundo cibernético. Há outras inteligências que ainda surgirão. Enfim, o educador é inteligente porque reconhece, estimula e celebra a multiplicidade ilimitada de inteligências.

O educador é menos profissional quando se apega em demasiado a uma só metodologia e crê, indevidamente, que ela se aplica sempre e a todos, esquecendo que cada educando e cada situação educacional são únicos. Sendo a arte a capacidade de customizar a aprendizagem para cada contexto, voltada a cada indivíduo, explorando a possibilidade de trilhas educacionais flexíveis, ancoradas em diversas metodologias e fazendo uso de múltiplos recursos tecnológicos.

Enfim, os professores, nos tempos atuais, caracterizados pela dominância das tecnologias digitais, progressivamente se aproximam de serem até artistas, dado que educação, cada vez mais, é arte. Temos menos receitas educacionais, as antigas já não funcionam e os desafios se tornaram mais complexos, demandando um repensar profundo de paradigmas, conceitos e valores. Os conteúdos, procedimentos e técnicas, alicerces da educação do século passado, são consistentes bases, a partir das quais cabe ao educador desenvolver a arte da aprendizagem mediada por novas tecnologias e metodologias inovadoras.

FAC- 0 Art. 210 da Constituição Federal e a Meta 02 do Plano Nacional de Educação tratam da Base Nacional Comum Curricular (BNCC), que deve garantir Aprendizagens Essenciais como Direitos dos Educandos no âmbito da Educação Básica Escolar. A Resolução CNE/CP n. 02/2017, do Conselho Nacional de Educação, considerou que estas Aprendizagens Essenciais são consideradas como equivalentes ao desenvolvimento de Competências para resolver demandas complexas da vida cotidiana. Considerando que o mesmo Conselho caracterizou essas Competências em termos de capacidade para mobilizar, articular e integrar Conhecimentos (conceitos e procedimentos), Habilidades (práticas cognitivas e socioemocionais), Atitudes e Valores, como você ressalta entre esses Valores o zelo pela Aprendizagem? 
RM- Ter habilidade não é, em si, garantia de competência. Por outro lado, ser competente demanda ter domínio mínimo das habilidades associadas. Ainda que "habilidade" e "competência" sejam distintas, a área de superposição entre as respectivas definições é enorme, ao ponto que nem sempre uma separação inequívoca é possível. Fruto de tal complexidade, inevitáveis confusões afloram, por vezes juntando, indevidamente, o que deveria ser distinto e, em outras, separando o que seria, talvez, indissociável.

Uma maneira tradicional e informal de classificá-las é assumir que habilidades compõem uma das três partes das competências. As outras duas seriam os conhecimentos e as atitudes. Nesse sentido, habilidades são capacidades adquiridas para desempenhar determinado papel ou função específicos. Competências, de caráter mais amplo, demandam agregar a essas habilidades um conjunto de conhecimentos e de atitudes para que uma determinada missão seja realizada.

Atualmente, mais relevante do que a separação e complementação entre competências e habilidades creio ser o quanto o educando aumentou sua compreensão e controle sobre o seu próprio processo de aprendizagem. O incremento do nível de consciência acerca de como ele aprende permitirá, em conjunto com os demais atores do processo, gerar estratégias educacionais personalizadas, que atendam suas particularidades e peculiaridades.

\section{FAC- Esteja à vontade para considerações complementares, que julgar necessárias e oportunas de serem incluídas nesta entrevista.}

RM- Em resumo, entendo que houve um período, em um passado bem recente, em que o domínio de determinado conteúdo, acrescido de alguns procedimentos e técnicas, poderiam ser suficientes para que um profissional atendesse plenamente às demandas daquela época.

O drama é que o tempo, inexoravelmente, flui, de modo que mudanças drásticas, rápidas e profundas estão em curso, alterando de forma radical esse contexto. As tecnologias digitais apontam, a passos acelerados, para uma sociedade em que a informação estará totalmente acessível, de forma instantânea e basicamente gratuita. Educacionalmente, aquilo que um dia havia sido suficiente permanece necessário, mas novos ingredientes e características adicionais estão presentes com a mesma importância.

Na Revolução Industrial e, especialmente, durante o século XX, os predicados de um bom profissional estavam associados aos padrões de produção nos moldes fordistas e tayloristas e nas competências que Ihe fossem compatíveis. O mundo contemporâneo apresenta desafios inimagináveis há poucas décadas, passando por novos aspectos essenciais associados ao processo de aprendizagem. Entre eles, destaco a metacognição. 
Denomina-se metacognição a esse conjunto de abordagens que transcende a cognição simples. As habilidades metacognitivas incluem o conhecimento acerca dos fatores associados ao desempenho na aprendizagem, o domínio de vários tipos de estratégias adotadas para aprender e saber customizar cada estratégia para situações específicas, bem como acompanhar o estabelecimento de planejamento e metas, especialmente dos resultados e das estratégias adotadas.

O estímulo para que os educandos reflitam sobre seus próprios processos e estratégias implica autorreflexão e aprender a trabalhar em equipe, incluindo a prática de entender o outro. Dessa forma, promove-se a aprendizagem colaborativa e independente, indispensável em um cenário de aprendizagem permanente ao longo da vida.

No processo formativo do educando, agregam-se às características tradicionais de natureza mais técnica um conjunto de elementos socioemocionais, os quais alguns enxergam como sendo uma recuperação de elementos humanísticos em contraposição às ênfases exclusivamente conteudistas. Tal dinâmica pode, igualmente, ser vista à luz da priorização dos instrumentais metacognitivos (saber aprender) em complemento à versão mais antiga de cognição simples.

Do ponto de vista dos empregadores de profissionais de nível superior e do aproveitamento de novas oportunidades de negócios por parte dos próprios formandos, aquilo que se aprende nas abordagens clássicas do ensino superior continua sendo indispensável, ainda que insuficiente, para as atividades do universo profissional atual. As abordagens inovadoras que privilegiam as habilidades metacognitivas serão, sim, as definidoras dos níveis de sucesso desses cidadãos ao longo do cumprimento de suas missões, sejam elas quais forem. 